\title{
THE CENTRAL ARTERY OF THE RETINA* ITS ROLE IN THE BLOOD SUPPLY OF THE OPTIC NERVE
}

\author{
BY \\ SOHAN SINGH HAYREH $\dagger$ \\ Institute of Ophthalmology, University of London \\ (Director of Research: Sir Stewart Duke-Elder)
}

THE blood supply of the optic nerve in man has been a subject of controversy. Much of the confusion seems to be due to attempts to cover a host of variations by rigid and dogmatic statements based on small series of specimens. The main controversial issues are:

(1) The role of the central retinal artery in the blood supply of the optic nerve.

(2) The existence of a central artery of the optic nerve.

(3) The existence and extent of the anastomoses between the central retinal artery and the arteries surrounding the optic nerve.

François and Neetens (1963), in their latest publication on the subject, have raised certain controversial issues which require comment for elucidation.

Because of great variations in the pattern of the central retinal artery, as was pointed out in a previous publication (Singh and Dass, 1960b), it is imperative that the number of specimens examined by each worker in this field should be known so that appropriate significance can be given to their views. Table I (overleaf) briefly summarizes the material and methods employed by the various workers.

For a study of the blood vessels of this nature, I think that a specimen in which the vessels are properly injected with liquid latex is the most informative; histological studies are at times likely to be misinterpreted and are not worth the labour and time spent on them, unless a study of the capillary network is required.

\section{(1) Role of the Central Retinal Artery in the Blood Supply OF THE OPTIC NERVE}

Branches from the extraneural part of the central retinal artery supplying the optic nerve have been described by Beauvieux and Ristitch (1924), Wolff (1939), Bignell (1952), Steele and Blunt (1956), Blunt (1956), Wybar (1956), myself (Singh and Dass, 1960b), and others. Similarly, intraneural

* Received for publication June 6, 1963.

$\dagger$ Beit Memorial Research Fellow. 
TABLE I

MATERIAL AND METHODS USED BY PREVIOUS AUTHORS

\begin{tabular}{|c|c|c|c|c|}
\hline Author & Date & $\begin{array}{c}\text { Total } \\
\text { No. of } \\
\text { Specimens } \\
\text { Examined }\end{array}$ & Method of Examination & $\begin{array}{l}\text { No. of Specimens with } \\
\text { Complete Filling of the } \\
\text { Central Retinal Artery } \\
\text { on Injection }\end{array}$ \\
\hline $\begin{array}{l}\text { Beauvieux and } \\
\text { Ristitch }\end{array}$ & 1924 & 20 & $\begin{array}{l}\text { Histology after Prussian } \\
\text { blue injection }\end{array}$ & $? 3$ \\
\hline Wolff & 1939 & $?$ & ? Histology & $?$ \\
\hline Wolff & 1940 & 1 & Histology & - \\
\hline Bignell & 1952 & $?$ & $\begin{array}{l}\text { Histology after injection } \\
\text { of India ink }\end{array}$ & $?$ \\
\hline $\begin{array}{l}\text { François and } \\
\text { Neetens }\end{array}$ & 1954 & 34 & Latex injection & $? 12^{*}$ \\
\hline $\begin{array}{l}\text { François, Neetens, } \\
\text { and Collette }\end{array}$ & 1955 & $?$ & Microangiography & $?$ \\
\hline $\begin{array}{l}\text { François and } \\
\text { Neetens }\end{array}$ & 1956 & $?$ & Histology & - \\
\hline $\begin{array}{l}\text { François and } \\
\text { Neetens }\end{array}$ & 1963 & 31 & $?$ & $?$ \\
\hline Wybar & 1956 & 17 & Latex injection & $? 17$ \\
\hline Blunt & 1956 & 34 & Latex injection & 9 \\
\hline Steele and Blunt & 1956 & 38 & Histology & - \\
\hline $\begin{array}{l}\text { Dejean, Viallefont, } \\
\text { Boudet, and } \\
\text { Costeau }\end{array}$ & 1957 & 2 & Histology & 一 \\
\hline \multirow[t]{3}{*}{ Singh and Dass } & \multirow[t]{3}{*}{1960} & 100 & Latex injection & 62 \\
\hline & & 2 & $\begin{array}{l}\text { Serial sections after } \\
\text { Prussian blue injection }\end{array}$ & 2 \\
\hline & & 4 & Serial sections & - \\
\hline
\end{tabular}

* It is difficult to make out the exact figure; twelve is based on the authors' description given below:

1. "Ophthalmic artery (Four times)-The whole tree was filled up, but the capillary regions were not all well filled.

2. Central retinal artery (Eight times)-The retina was very well injected, and also at times a few pial vessels.

3. Central optic nerve artery (Six times) - The optic nerve was filled to the centre, and the lamina cribrosa completely.

4. Short posterior ciliary artery (Once)."

branches from the central retinal artery to the optic nerve have been described by Magitot (1908), Quain (1909), Beauvieux and Ristitch (1924), Whitnall (1932), Abbie (1938), Bignell (1952), Wybar (1956), Steele and Blunt (1956), Blunt (1956), and myself (Singh and Dass, 1960b). On the other hand, Wolff (1939), François and others (1954, 1955, 1956, 1963), and Dejean, Viallefont, Boudet, and Costeau (1957) found no intraneural branches and François and his colleagues considered that only inconstant early retinal branches occurred. 
The numbers of branches in my series (Singh and Dass, 1960b), which arise from the different parts of the central retinal artery, are shown in Table II.

TABLE II

BRANCHES FROM THE CENTRAL ARTERY OF THE RETINA

\begin{tabular}{|c|c|c|c|}
\hline \multirow[t]{2}{*}{ Number of Branches Observed } & \multicolumn{3}{|c|}{$\begin{array}{l}\text { Percentage of Specimens Examined in which Branches } \\
\text { from Various Points were Seen }\end{array}$} \\
\hline & Intra-orbital & Intravaginal & Intraneural \\
\hline $\begin{array}{c}0 \\
1 \\
2 \\
3 \\
4 \\
5 \\
6 \\
7 \\
8 \\
\text { Uncertain* }\end{array}$ & $\begin{array}{r}47 \cdot 8 \\
32 \cdot 6 \\
13 \cdot 0 \\
2 \cdot 2 \\
2 \cdot 2 \\
1 \cdot 1 \\
= \\
= \\
1 \cdot 1\end{array}$ & $\begin{array}{r}5 \cdot 3 \\
48 \cdot 7 \\
35 \cdot 5 \\
6 \cdot 6 \\
= \\
= \\
= \\
\overline{4} \cdot 0\end{array}$ & $\begin{array}{l}25 \cdot 0 \\
26 \cdot 6 \\
20 \cdot 3 \\
10 \cdot 9 \\
10 \cdot 9 \\
\frac{-}{1 \cdot 6} \\
\frac{1}{1 \cdot 6} \\
3 \cdot 1\end{array}$ \\
\hline Total No. of Specimens Examined $\dagger$ & 92 & 76 & 64 \\
\hline
\end{tabular}

* These include those specimens which were distorted during maceration, so that the exact number and distribution of branches present could not be ascertained.

$\dagger$ Including all the latex-filled specimens, and two serial reconstructions after Prussian blue injection.

The intra-orbital branches usually supply the dural sheath of the optic nerve, and in about half the specimens they also ramify on the pia to supply the nerve. The intravaginal branches, which are the commonest and generally among the most prominent, are invariably pial branches and at times these behave like intraneural branches. The pial branches (i.e. from the intra-orbital and intravaginal parts and rarely from the intraneural part) ramify on the pia, always anterior to the site of entry of the central retinal artery into the nerve and in about half the specimens also posterior to this, sometimes extending as far back as the optic canal. These always supply the inferior aspect of the nerve, and also in about half the specimens the lateral side, in slightly less than half the medial side, and much less frequently the superior aspect as well. The pial branches of the central retinal artery, along with the pial branches from other sources (e.g. recurrent pial branches of the circle of Zinn, choroidal arteries, and collateral branches of the ophthalmic artery) constitute the centripetal vascular system of the optic nerve (Figs 1 and 2, overleaf).

The intraneural branches constitute the centrifugal or axial vascular system of the nerve mainly in the region containing the central vessels, and at times even behave like pial branches, as described above.

Beauvieux and Ristitch (1924) and Wybar (1956) described branches arising from the intraneural part of the artery, some of which terminated in the substance of the nerve while, according to Wybar (1956), others anastomosed with branches from the pial arterial plexus. According to Blunt (1956), all the optic nerves examined by him by various techniques "in which evidence 


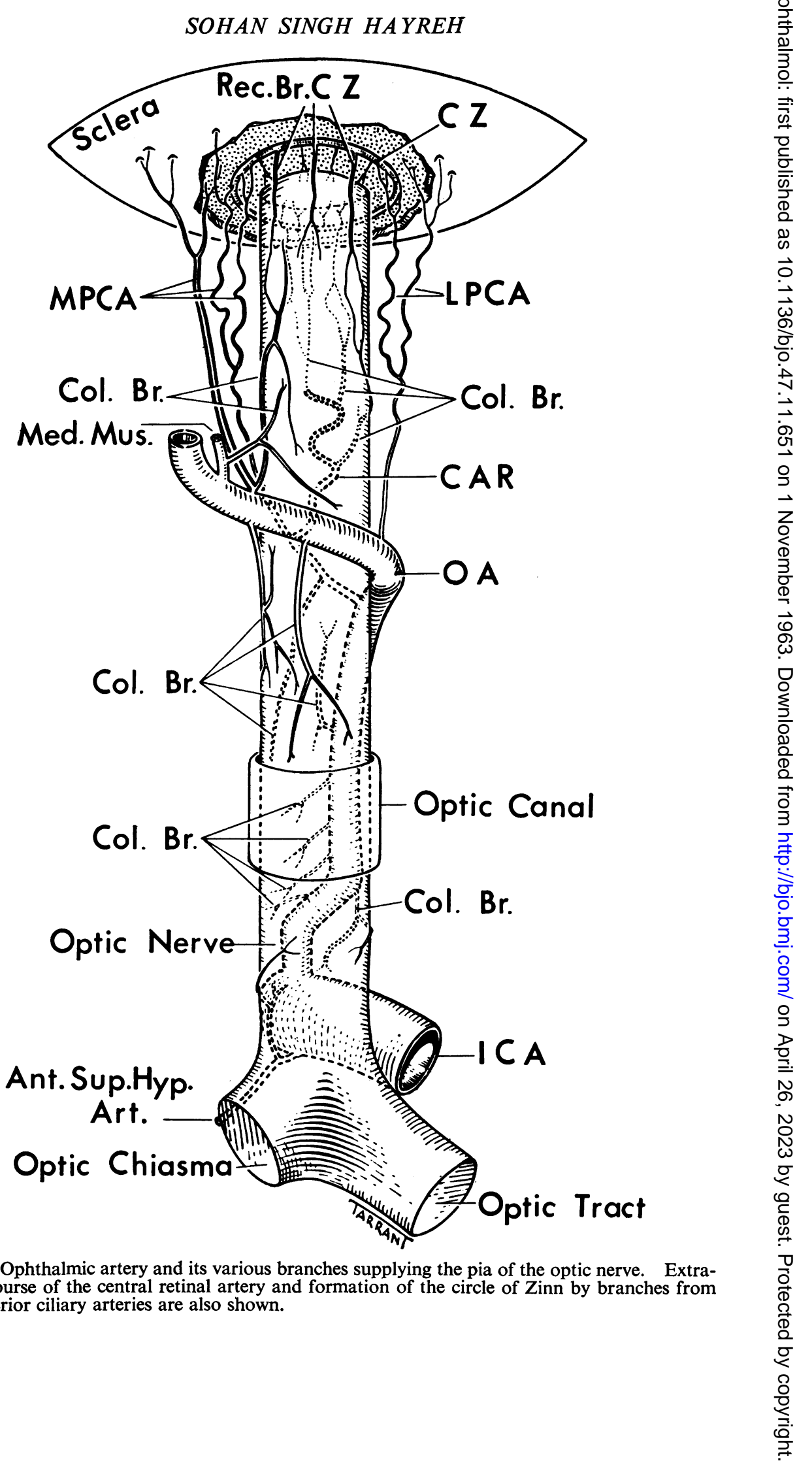

FIG. 1.-Ophthalmic artery and its various branches supplying the pia of the optic nerve. Extraneural course of the central retinal artery and formation of the circle of Zinn by branches from the posterior ciliary arteries are also shown. 


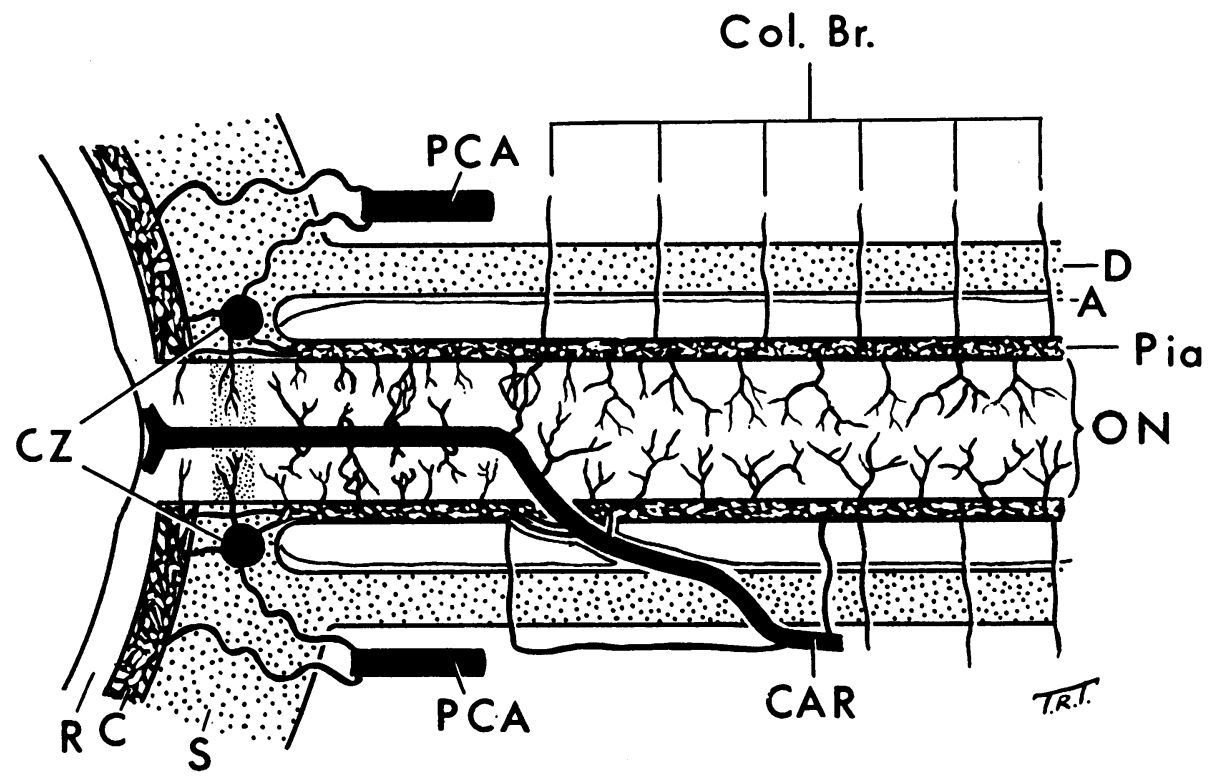

Fig. 2.-Arterial supply of the optic nerve.

$\begin{array}{ll}\text { A } & =\text { Arachnoid } \\ \text { Ant. Sup. Hyp. Art. } & =\text { Anterior superior hypophysial artery } \\ \text { C } & =\text { Choroid } \\ \text { CAR } & =\text { Central artery of retina } \\ \text { Col. Br. } & =\text { Collateral branch } \\ \text { CZ } & =\text { Circle of Zinn } \\ \text { LPCA } & =\text { Lateral posterior ciliary artery } \\ \text { Med. Mus } & =\text { Medial muscular artery } \\ \text { MPCA } & =\text { Medial posterior ciliary artery } \\ \text { OA } & =\text { Ophthalmic artery } \\ \text { ON } & =\text { Optic nerve } \\ \text { PCA } & \text { = Posterior ciliary artery } \\ \text { R } & =\text { Retina } \\ \text { Rec. Br. } & =\text { Recurrent branch } \\ \text { S } & =\text { Sclera }\end{array}$

of intraneural branching of the central retinal artery was specifically sought, its presence was detected. It is therefore suggested that the purely negative evidence on which such intraneural branches have been denied is based on failure to inject the central retinal artery adequately". He added that "pial branches of the arteria centralis retinae were constantly found". With these views of Blunt (1956) my findings agree.

François and Neetens (1954) state that the central retinal artery is "strictly terminal and gives off no branches throughout its course, apart from some small ones to the pial network", which are present only rarely and are small in size. They emphatically denied any contribution to the optic nerve by the central retinal artery, asserting that "if the central retinal artery does give off a few fortuitous branches at the level of the lamina cribrosa, they are destined to reach the retina and papilla and not the optic nerve". This was further reiterated by the same authors in 1956: "In the optic nerve 
itself there is a complete absence of nutritive collaterals of the central retinal artery". In their latest publication (1963), they state that "branching is rare and variable" from the intra-orbital part; during its course in the optic nerve sheath (i.e. its intravaginal part) "it gives off one branch (or very rarely two) in a constant fashion". They add "Detailed examination of the data published by Singh and Dass (1960) regarding intraneural branches of the central retinal artery, yielded the following percentages: in only $17 \cdot 2$ per cent. of cases the central retinal artery has four or more branches (four branches 10.9 per cent.; five branches 0 per cent.; six branches 1.6 per cent.; seven branches 0 per cent.; eight branches 1.6 per cent.; dubious 3.1 per cent.). In 82.8 per cent. of cases the central retinal artery has 0 to 3 branches $(0$ branches 25 per cent.; one branch 26.6 per cent.; two branches 20.3 per cent.; three branches 10 per cent.).... Thus it is seen that, in the majority of cases (82.8 per cent.)* the central retinal artery has one or two intraneural branches or none. These figures agree well with our own findings". Since, in my series (Singh and Dass, 1960b), 75 per cent. always had intraneural branches varying in number from one to eight (Figs 9, 10, 11, 12, 13, 14, and 15 of Singh and Dass, 1960b), while only 25 per cent. had no intraneural branches, it cannot be said that these findings agree with the conclusion of these authors that "in the optic nerve itself there is a complete absence of nutritive collaterals from the central retinal artery" (François and Neetens, 1956, 1963).

In my series I found that, in $42 \cdot 2$ per cent. of specimens, branches arose from all the three parts of the central retinal artery (Fig. 2); in $3 \cdot 1$ per cent. such branches were absent, while in the rest the branches were distributed variably from the different parts. In about 95 per cent. of specimens, the central retinal artery contributed to the blood supply of the anterior part of the nerve, mostly assuming a major role but assisted by recurrent pial branches from the circle of Zinn, the choroidal arteries, and collateral branches from the ophthalmic and other orbital arteries. Except for one out of 64 specimens (with the intraneural part completely filled), no intraneural branch of the central retinal artery ever supplied the retina as claimed by François and others $(1954,1955,1956,1963)$. Steele and Blunt (1956) and other workers also failed to find any such condition. In support of the absence of intraneural branches from the central retinal artery, François and Neetens (1963) quoted Dejean and others (1957) who also found none, but it is to be noted that the opinion of the latter was based on only two specimens.

A large number of photographs showing branches from the different parts of the central retinal artery, as seen in latex-filled specimens, and also histological sections have been presented in my previous publications on this subject (Hayreh, 1958; Hayreh and Dass, 1959; Singh and Dass, 1960a, 1960b) and also in those of Steele and Blunt (1956) and Wybar (1956); these leave no ambiguity about their existence and distribution and the region supplied.

* It should be 71.9 per cent. 
François and Neetens (1963), speaking of the site of origin of intraneural branches, state that "Singh and Dass (1960) do not mention the exact site where most of these branches are given off"'. In the paper referred to by them, I mentioned that "the branches from the intra-orbital part of the artery arose all along its course; those from the intravaginal part mostly arose from its distal half, particularly near its point of entry into the optic nerve, and those from the intraneural part were evenly distributed, except that there were very few from the distal third and more from the middle third of the horizontal section. No branches arose at the level of the lamina cribrosa". These observations are in sharp contrast with the views of François and Neetens (1963), according to which "these usually originated from the central retinal artery in the anterior third part of its intraneural course, immediately behind the lamina cribrosa"; these branches, according to them, are early retinal branches and do not supply the optic nerve, whereas I found that all these intraneural branches supplied the nerve, a view supported by Steele and Blunt (1956) who found that they arose mostly near the middle of the intraneural part.

To prove the absence of any contribution by the central retinal artery towards the blood supply of the optic nerve, François and Neetens (1963) described filling-in of the nerve on injection of an ophthalmic artery, after eliminating the central retinal artery by ligating it at its origin, without any filling in of the central retinal artery. In my similar injection experiments with latex and coloured watery solutions, I found the filling-in of the central retinal artery in all those specimens, from the posterior ciliary arteries and the collateral branches of the ophthalmic artery to the optic nerve, through their pial anastomoses. The reverse of this procedure, i.e. injection into the central retinal artery alone, generally filled the posterior ciliary arteries, and also the collateral arteries from the ophthalmic artery. In two specimens in which I injected 3 per cent. Prussian blue solution into the central retinal artery alone, serial sections showed pial branches from the central retinal artery supplying the optic nerve nearly up to the centre of the nerve at places (Fig. 8, Singh and Dass, 1960b) and the central retinal artery in these specimens had no intraneural branch. The posterior ciliary arteries in these two were filled in through the pial anastomoses. The central retinal artery thus supplies the optic nerve in the vast majority of specimens, although in about 5 per cent. no supply from the central retinal artery to the optic nerve can be seen. The injection experiment given above by François and Neetens (1963) may belong to the latter category-an exception but not a rule.

Capillary branches arising from the central retinal artery in the region of the lamina cribrosa have been described by Nettleship (1876), Leber (1903), Coats (1905), Gonin (1905), Parsons (1906), Quain (1909), RochonDuvigneaud (1933), Wolff (1940), Igersheimer (1942), Duke-Elder (1932), Traquair (1949), Wexler (1950), Wybar (1956), and Dejean and others (1957). On the other hand, no branches from this region were observed by 
Beauvieux and Ristitch (1924), Behr (1935), Kershner (1943), Bignell (1952), François and others $(1954,1955,1956,1963)$, Steele and Blunt (1956) and myself (Singh and Dass, 1960b). I did at times find branches from the central retinal artery just posterior to the lamina cribrosa, resembling those shown in the casts of Wybar (1956), and they possibly supplied the lamina cribrosa. Unlike Wybar (1956) I grouped those as intraneural branches. Wolff (1939) initially denied their existence in the lamina cribrosa but later found one on examining sections of the lamina cribrosa (Wolff, 1940). Apparently the majority of specimens have no branch from the central retinal artery in the region of the lamina cribrosa, while a few have minute branches, but they have practically no functional significance in restoring the collateral circulation in the event of occlusion of the central retinal artery because of their capillary nature. As I have pointed out earlier (Hayreh, 1963), the capillaries in the region of the lamina cribrosa are continuous in front with those of the disc, and behind with the adjoining optic nerve. Because the optic disc and the part of the optic nerve adjoining the lamina cribrosa are usually supplied by the central retinal artery, it could be considered that the lamina was partly supplied from the central retinal artery even if the artery did not give out any branch in this region.

\section{(2) Central Optic Nerve Artery}

An artery which on reaching the centre of the optic nerve divides into two branches-one running forwards to the region of the lamina cribrosa and the other backwards to reach the optic foramen-has been described in the literature. It was designated "arteria collateralis centralis retinae" by Wolff (1939), "anterior and posterior optic nerve arteries" by Behr (1935), and "central optic nerve artery" by François and others (1954, 1955, 1956, 1963). According to Wolff (1939), it arises from the central retinal artery as the latter pierces the dural sheath of the optic nerve. Behr (1935) found it arose from the bend of the central retinal artery in the centre of the optic nerve, and François and Neetens (1954) described its origin from the ophthalmic artery proximal to the origin of the central retinal artery though in their last paper (François and Neetens, 1963) they say that it may sometimes be a branch of the initial part of the central retinal artery. Wybar (1956) found a somewhat similar artery arising (either as one artery later dividing into two branches, or as two separate branches) from the central retinal artery where the latter pierces the optic nerve, but he could not trace these forwards and backwards in the centre of the optic nerve for a long distance. The anastomoses of the anterior division at the lamina cribrosa with the circle of Zinn, as described by François and Neetens (1954) have not been reported by Behr (1935), Wolff (1939), or Wybar (1956).

The existence of such an artery was denied by Steele and Blunt (1956), Blunt (1956), and Dejean and others (1957); it was not seen by Beauvieux and Ristitch (1924) or by Bignell (1952). 
In my previous publication (Singh and Dass, 1960b), I remarked: "None of the specimens in the present series showed a typical central artery of the optic nerve conforming to the description given above, but in eight a minor representation of this artery was seen. The length of the anterior and posterior optic nerve arteries is very variable, the anterior being usually longer and the posterior much shorter. Unlike the description given by some authors, these were seen to run in each direction for 3 to $4 \mathrm{~mm}$., except that one anterior branch ran forward for $6 \mathrm{~mm}$. These branches did not reach the lamina cribrosa or the optic foramen in any specimen. They arose from the intravaginal part in two specimens, from the vertical section of the intraneural part in five, and from the fourth bend* of the central retinal artery in one. Thus the occurrence as well as the course of this collateral artery is both inconstant and variable".

In spite of this description of mine, François and Neetens (1963), commenting on the existence of this artery, state that "Singh and Dass (1960b) neither deny nor mention its existence". A little later in the same paper they say "It is indeed surprising that Singh and Dass (1960) never found any such branch".

François and his colleagues $(1954,1955,1956,1963)$ are the only authors, in the whole literature on the subject, who have described this artery as arising from the ophthalmic artery in a majority of their specimens or from the initial part of the central retinal artery. They have very emphatically stated that "a central artery of the optic nerve undoubtedly exists" (François and Neetens, 1956) and have recently reiterated their opinion (François and Neetens, 1963) by saying that "the existence of such an artery in the optic nerve is beyond all doubt". Throughout my investigations I have been particularly careful to look for this artery and the whole investigation was done under the dissection microscope, using a magnification up to $\times 100$ (Singh and Dass, 1960a, 1960b; Hayreh, 1962), but I have never found any such artery arising directly from any part of the ophthalmic artery or from the intraorbital part of the central retinal artery. Blunt (1956) also stated: "In no specimen was there evidence of true anterior or posterior axial vessels or of a central artery of the optic nerve (François and Neetens, 1954), though injections were always made proximal to the described point of origin of the latter vessel from the ophthalmic artery. These findings confirm Wybar's observations.... It is noteworthy, in this connexion, that François and Neetens (1954) do not record having injected both the central retinal artery and the central artery of the optic nerve in any individual specimen". With these views of Blunt (1956) I fully agree. If the central optic nerve artery arising from the ophthalmic artery or the intra-orbital part of the central retinal artery was so commonly seen, as stressed so emphatically by François and Neetens $(1956,1963)$, surely it must have been noticed by other workers both

* In the centre of the optic nerve. 
before and since their description (François and Neetens, 1954). But, in fact, this central optic nerve artery of their description has not been seen by any other investigator. The total number of specimens in the available literature in which it has not been seen is 238 (20 of Beauvieux and Ristitch, 1924; 17 of Wybar, 1956; 72 of Blunt, 1956, and Steele and Blunt, 1956; 2 of Dejean and others, 1957; 106 of Singh and Dass, 1960; and 21 in which François and Neetens themselves did not claim to have seen it). This figure may be compared with the ten specimens in which François and Neetens (1963) claim to have found it. Evidently, if the central artery of the optic nerve conforming to the description of François and others (1954, 1955, 1956, 1963) exists at all, it is so extremely rare as to be of no practical significance.

It seems that the existence of the central artery of the optic nerve has been stipulated by François and his colleagues as a prerequisite to their so-called "vascular pseudo-papillitis"-a somewhat unfortunate term (see Huber, 1961; Hoyt, 1962). No histopathological proof is available in support of such a hypothesis.

It is stated by François and others $(1954,1955,1956,1963)$ that the anterior division of the central optic nerve artery acts as a vasa vasorum for the intraneural part of the central retinal artery. The vasa vasorum supplies only the large arteries, e.g. aorta, carotids, etc., and not the small arteries of the size of the central retinal artery. There is no histological evidence of the existence of any such vessels in the wall of the central retinal artery.

\section{(3) Anastomoses of the Central Retinal Artery}

François and Neetens (1963) emphatically state "we are unable to demonstrate any anastomoses at any level whatsoever". There is, however, plenty of evidence in the literature regarding the establishment of such anastomoses by the central retinal artery. Meyer (1887) and Tichomiroff (1900) described anastomoses between the optic nerve branches of the central retinal artery and the posterior ciliary artery. Wybar (1956) described the formation of a dense pial arterial plexus of the optic nerve by branches from the short posterior ciliary arteries, central retinal artery, and the circle of Zinn. Nettleship (1876), Leber (1903), Coats (1905), Gonin (1905), Parsons (1906), Quain (1909), and Rochon-Duvigneaud (1933) described more direct anastomoses between the central retinal artery and the choroidal arteries. Wybar (1956) showed anastomoses between the intraneural branches of the central retinal artery and the pial arterial plexus. Anastomoses between the branches of the circle of Zinn and those of the central retinal artery in the region of the lamina cribrosa have been described by Nettleship (1876), Leber (1903), Coats (1905), Gonin (1905), Parsons (1906), Quain (1909), Duke-Elder (1932), Rochon-Duvigneaud (1933), Wolff (1940), Vail (1948), Traquair (1949), Igersheimer (1942), Wexler 
(1950), and Wybar (1956); and have been denied by Magitot (1908), Beauvieux and Ristitch (1924), Behr (1935), Wolff (1939), Kershner (1943), Bignell (1952), François and others (1954, 1955, 1956, 1963), and Steele and Blunt (1956). I myself have not seen any such anastomoses in the region of the lamina cribrosa. Most of the authors who have suggested that they exist have assumed that any branches given off by the central artery of the retina in this region must form anastomoses with the branches from the circle of Zinn-such evidence is merely circumstantial.

Beauvieux and Ristitch (1924) and Steele and Blunt (1956) did not mention that any anastomoses were established by the central retinal artery anywhere.

I found numerous anastomoses established by the central retinal artery (Figs 15, 16, 17, 18, 19, 21, and 23 of Singh and Dass 1960b), mostly in the pia of the optic nerve and particularly between the pial branches of the central retinal artery and the recurrent pial branches of the circle of Zinn and choroidal arteries (Figs 1 and 2). For this reason the injection of fluids into the central retinal artery fills the posterior ciliary arteries and vice versa. The next most common group was that of the anastomoses between the pial branches of the central retinal artery and the pial collateral branches from the ophthalmic artery. When the coloured latex was injected into the ophthalmic artery after ligating all branches of the ophthalmic artery, including the central retinal artery but leaving the collateral branches to the optic nerve intact, the latex filled the central retinal artery through these anastomoses. Occasionally the anastomoses of the central retinal artery were seen within the substance of the optic nerve. No anastomoses were, however, seen in the region of the lamina cribrosa. The anastomoses established by the central retinal artery were usually large enough to be of considerable physiological significance, especially those located on the pia. Their size can be judged from the various photographs published in my previous paper (Singh and Dass, 1960b).

\section{ConClusions}

(1) As a rule the central retinal artery gives off branches (in about 97 per cent. of my series). About 50 per cent. of my specimens had branches from the intra-orbital part (1-5 branches), about 95 per cent. from the intravaginal part (1-3 branches), and about 75 per cent. from the intraneural part (1-8 branches). These branches supply the optic nerve and its dural sheath. In each case they supplied the optic nerve anterior to the site of entry of the central retinal artery into the nerve, and in about half, in addition, the part of the optic nerve posterior to the site of entry and extending at times as far back as the optic canal. In the anterior part of the optic nerve, the pial branches constitute the centripetal vascular system while the intraneural branches constitute the centrifugal vascular system. It follows that the central retinal artery has a major role in the blood supply of the anterior part 
of the optic nerve in a majority of cases, contributing to both the peripheral and the axial systems. It contributes in various degrees to the blood supply of the rest of the orbital and the canalicular part of the nerve.

(2) No central artery of the optic nerve (as described by François and others, 1954, 1955, 1956, 1963) has been seen by me or by any other worker in this field. Only on rare occasions have I observed minor arteries as described by Wolff (1939) and Wybar (1956) which cannot be considered of any greater functional or structural significance than the other intraneural branches of the central retinal artery.

(3) Important anastomoses are usually established by the pial branches of the central retinal artery with the recurrent pial branches of the circle of Zinn and choroidal arteries, and with the pial collateral branches from the ophthalmic artery and other orbital arteries. Anastomoses at other places are also occasionally seen.

In view of the extreme degree of variation in the pattern of the branches and anastomoses of the central retinal artery, it would be foolish for me to be absolutely dogmatic. Some rare specimen may possibly show a pattern similar to that described by François and others (1954, 1955, 1956, 1963), but only as an example of normal anatomical variation.

I am greatly indebted to Mr. T. Tarrant, of the Medical Illustration Department of the Institute of Ophthalmology, who took great pains to prepare the illustrations for me.

I wish also to express my thanks to Miss B. Jenkins for her secretarial help.

\section{REFERENCES}

AbBie, A. A. (1938). Med. J. Aust., 2, 199.

BeAuvieuX, J., and RistrTch, K. (1924). Arch. Ophtal., 41, 352.

BEHR, C. (1935). v. Graefes Arch. Ophthal., 134, 227. (Cited by Kershner; Traquair; Wolff.)

Bignell, J. L. (1952). Trans. ophthal. Soc. Aust., 12, 105.

Blunt, M. J. (1956). Proc. roy. Soc. Med., 49, 433.

Coats, G. (1905). Roy. Lond. ophthal. Hosp. Rep., 16, 262.

Dejean, C., Viallefont, Boudet, and Costeau (1957). Bull. Soc. ophtal. Fr., p. 548.

DUKE-ELDER, S. (1932). "Text-book of Ophthalmology", vol. 1, p. 139. Kimpton, London.

François, J., and NeEtens, A. (1954). Brit. J. Ophthal., 38, 472.

FRANÇOIS, J., (1956). Ibid., 40, 45.

(1963). Ibid., 47, 21.

- - and Colletre, J. M. (1955). Ibid., 39, 220.

GonIN, J. (1905). Ann. Oculist. (Paris), 133, 167.

HAYREH, S. S. (1958). M.S. Thesis, Panjab University. (1962). Brit. J. Ophthal., 46, 212.

(1963). Anales del Instituto Barraquer, vol. 4, No. 1, p. 7.

and Dass, R. (1959). In "XVIII Conc. Ophthal. 1958, Belgica Acta", vol. 2, p. 1345. Imprimerie Médicale et Scientifique, Bruxelles.

HoYt, W. F. (1962). Arch. Ophthal., 68, 654.

Huber, A. (1961). "Eye Symptoms in Brain Tumors", p. 111. Mosby, St. Louis.

IGERSHEIMER, J. (1942). Ophthalmologica (Basel), 103,'230. (Cited by Vail; Traquair.)

KERSHNER, C. M. (1943). "Blood Supply of the Visual Pathway". Meador, Boston.

LEBER, T. (1903). In "Graefe-Saemisch Handbuch der gesamten Augenheilkunde", 2nd ed., Bd. 2, Abt. 2. Engelmann, Leipzig. (Cited by Beauvieux and Ristitch; Wolff; Wybar; François and Neetens.)

Magrtot, A. (1908). Thèse de Paris. Vigot Frères, Paris. (Cited by Beauvieux and Ristitch; Wolff; Wybar.) 
MEYER, F. (1887). Morph. Jb., 12, 414. (Quoted by Sudakevitch, 1947.)

NeTTLESHip, E. (1876). Brit. med.J., 1, 161.

PARSONS, J. H. (1906). "The Pathology of the Eye", vol. 3, p. 950. Hodder and Stoughton, London.

QuAIN, J. (1909). See Schäfer and Symington (1909).

Rochon-Duvigneaud, A. (1933). "Recherches sur l'oeil et la vision chez les vertébrés". Barnéoud, Laval. (Cited by François and Neetens.)

SchäfER, E. A., and Symington, J. (1909). In "Quain's Elements of Anatomy", 11th ed., vol. 3, pt. 2, pp. 222, 248. Longmans, Green, London.

Singh, S., and DASS, R. (1960a). Brit. J. Ophthal., 44, 193.

- (1960b). Ibid., 44, 280.

Steele, E. J., and Blunt, M. J. (1956). J. Anat. (Lond.), 90, 486.

SUDAKEVITCH, T. (1947). Brit. J. Ophthal., 31, 738.

Tichomiroff, M. A. (1900). "Variations of the Arteries and Veins of the Human Body". Kiev. (Quoted by Sudakevitch, 1947.)

TraquaIR, H. M. (1949). "An Introduction to Clinical Perimetry", 6th ed., p. 299. Kimpton, London.

VAIL, D. (1948). Amer. J. Ophthal., 31, 1.

WEXLER, D. (1949). In C. Berens, "The Eye and Its Diseases", 2nd ed., p. 59. Saunders, Philadelphia.

Whitnall, S. E. (1932). "The Anatomy of the Human Orbit", 2nd ed., p. 306. Oxford University Press, London.

WolfF, E. (1939). Trans. aphthal. Soc. U.K., 59, 157.

(1940) Ibid. 60, 69.

Wybar, K. C. (1956). Brit. J. Ophthal., 40, 65. 